\title{
INTENTIONS TO PARTICIPATE IN ADOLESCENT TRAINING PROGRAMS: EVIDENCE FROM UGANDA*
}

\author{
ORIANA BANDIERA ${ }^{\dagger}$ SELIM GULESCI ${ }^{\ddagger}$ \\ ROBIN BURGESS ${ }^{\S}$ IMRAN RASUL $^{\text {ฯ }}$ \\ MARKUS GOLDSTEIN" MUNSHI SULAIMAN**
}

NOVEMBER 2009

\begin{abstract}
Almost one third of the population in developing countries is under age 15. Hence improving the effectiveness of policy interventions that target adolescents might be especially important. We analyze the intention to participate in training programs of adolescent girls in Uganda, a country with perhaps the most skewed age distribution anywhere in the world. The training program we focus on is BRAC's Adolescent Development Program, which emphasizes the provision of life skills and entrepreneurship training, and microfinance. We find that girls who are more likely to benefit from the program are more likely to intend to participate. The program also attracts girls who are likely to place a high value on financial independence: single mothers and girls that are alienated from their families. The program attracts girls who are more likely to benefit from training: girls who believe they could be successful entrepreneurs but currently lack the quantitative skills to do so. Reassuringly, girls that are in school full-time are less likely to intend to participate. We also find that the program attracts girls from poorer villages but we find no evidence that poorer girls within each village are more likely to want to participate. Finally, girls from villages that have previously been exposed to NGO projects are less likely to intend to participate. The results have implications for the design, management, and evaluation of similar programs throughout East Africa.
\end{abstract}

Keywords: adolescent, intent to participate, training programs.

JEL Classification: J24, $015,016$.

\footnotetext{
${ }^{*}$ We are grateful to Proloy Barua, Imran Matin, Abebual Zerihun, and all those at BRAC that have made this study possible. We have also received excellent research assistance from Niklas Buehren. Funding from DFID and the World Bank's Gender Action Plan fund is gratefully acknowledged. We have also benefitted from comments from Stefano DellaVigna, Jakob Svensson, an anonymous referee, and participants at the 2009 EEA conference in Barcelona. The views expressed herein are those of the authors and do not necessarily reflect the views of any of the funders. All errors remain our own.

${ }^{\dagger}$ London School of Economics and Political Science, E-mail: o.bandiera@lse.ac.uk.

${ }^{\ddagger}$ London School of Economics and Political Science, E-mail: s.gulesci@lse.ac.uk.

$\S$ London School of Economics and Political Science, E-mail: r.burgess@lse.ac.uk.

ฯUniversity College London, E-mail: i.rasul@ucl.ac.uk.

"World Bank, E-mail: mgoldstein@worldbank.org.

**London School of Economics and Political Science, and BRAC, E-mail: m.sulaiman@lse.ac.uk.
} 


\section{Introduction}

There are enormous differences in age structures between rich and poor countries. There are more than two billion young people below age twenty in less developed regions. In proportionate terms, one third of the population in less developed countries is under age 15, while the corresponding figure is less than one fifth in more developed countries. Hence in developing countries there are large cohorts exiting education and entering the labor market each year. This transition might be particularly harsh for girls because they have poorer access to finance and information; they are disproportionately responsible for domestic duties; they are subject to stronger norms that hinder labor mobility; and with certain notable exceptions, there often exists at least a perception of employer bias towards hiring male employees [Katz 2008]. These differences in constraints across genders translate into significant differences in economic outcomes. For example, Fares et al [2006] document that in developing countries, 34\% of young women are out of the labor force, unemployed, or not in school, while the corresponding figure for men is $21 \%$.

Many female targeted youth employment programs focus on vocational training, emphasizing: (i) working with local training providers; (ii) the provision of training explicitly designed to meet the needs of local firms; (iii) the encouragement of female participation often including the provision of child care stipends. Although rigorous evaluations remain scarce, the evidence suggests significantly higher benefits of participation for young women [Attanasio et al 2008]. However, it is unclear whether such interventions can be effectively applied to settings in Africa where training providers are scarce, the formal sector is small, and there are more binding constraints on female movement and labor market access.

This paper contributes to this debate by studying the Adolescent Development Program (ADP), designed and implemented by BRAC, an international NGO. We focus on the ADP program in Uganda, although it is being replicated throughout sub-Saharan Africa, and is adapted from an ADP implemented in Bangladesh. The ADP is targeted towards adolescent girls aged between 14 and 20, during their transition from school to work. Its multi-dimensional 'livelihood' approach involves training related to life skills, entrepreneurial skills, and microfinance. There is little reliance on local firms or other private training providers.

In this paper we use the baseline data from our RCT evaluation of the ADP to document the factors that determine adolescent girls' intention to participate in an ADP-like program. As the data we exploit is collected at baseline, in this paper we have no data on actual participation, nor do we attempt to evaluate any aspect of the program. Rather, we focus on understanding the individual, household, and village level determinants of girls' intentions to participate. ${ }^{1}$

At the individual level, we provide evidence on whether adolescent girls that are likely to exhibit the highest marginal private benefits of participation are indeed more likely to participate, or whether the benefits accrue mostly to those girls that would have been likely to experience better labor market outcomes even without the program. We find that girls who could benefit more from financial independence, namely single mothers and girls who are alienated from their families, are more likely to intend to participate. Moreover, we find that girls who could benefit more from business training, namely girls who believe they could be successful entrepreneurs but currently lack the quantitative skills to do so, are also more likely to want to participate. We also shed light on whether programs designed to foster labor market skills encourage girls to drop out of formal schooling, which is obviously a key concern in the design of such policies. Reassuringly,

\footnotetext{
${ }^{1}$ There is a long literature in economics trying to understand the non-participation of eligible individuals or households into social assistance programs. Since the seminal contribution of Moffitt [1983] this literature has explored the role of welfare stigma, transaction costs, and imperfect information as potential explanations. A more recent literature emphasizes how the presentation and framing of choices affects take-up [Madrian and Shea 2001, Saez 2009, Bertrand et al 2010].
} 
we find that girls who are full-time in school are significantly less likely to intend to participate.

Village characteristics also drive intentions to participate. The program attracts girls from poorer villages but poorer girls within each village are no more likely to participate. Finally, girls from villages that have previously been exposed to NGOs are less likely to participate, suggesting NGO activities may have externalities on other NGOs.

Understanding the intent to participate, before actual take-up decisions is important. Most assistance programs are designed with voluntary take-up. This nearly always leads to selection into the program. Our analysis identifies ex ante the likely beneficiaries of the program and sheds light on the constraints to participating. This allows programs to be fine tuned in terms of their components, targeting strategy, or scaling-up strategy. ${ }^{2}$

\section{The Adolescent Development Program (ADP)}

\subsection{Program Design, Evaluation, and Data}

The ADP operates at a village level. Within a village, an adolescent development club (ADC) is set up to provide training activities. Each ADC has between 20 and 35 girls. The intended recipients are girls aged 14 to 20 although in practice, given field staff are unlikely to turn away girls and that ages are hard to verify, girls aged between 10 and 25 are potential beneficiaries.

The ADP has two elements: training and microfinance. Participants are provided with life skills and entrepreneurship training. Life skills training courses are designed to enhance girls' self-confidence and knowledge. Two girls from each ADC volunteer to be trained to run the club on a daily basis. They manage the ADC activities and facilitate the life skills training courses. The entrepreneurship training courses are provided by BRAC professionals. The second component of the ADP is microfinance. An age limit of 18 is set for girls to be eligible to graduate into microfinance typically one year after the ADCs initiation and after the livelihood and entrepreneurship training is completed. The primary cost of participation is time. ADCs meet for an hour a day, five days a week, and training courses are time intensive. Many of the entrepreneurship courses and the life skills courses last twenty days. ${ }^{3}$

This paper is part of a larger evaluation of the ADP. We focus here on aspects of the research design that are relevant to understand and learn from adolescent girls' intention to participate in an ADP-like program, as expressed in a baseline survey and prior to respondents having knowledge of whether their village had been assigned to actually receive the ADP. Two thirds of villages are randomly assigned to be treated with the ADP. It is not a pre-requisite for BRAC to already operate in the village for the village to be surveyed. Post-randomization, our survey instruments are fielded in treatment and control villages. In treated villages BRAC advertises the program door-to-door promotion and girls choose to participate or not.

We interviewed around 35 girls in each village. As girls might reside in the household of their parents, of their parents-in-law, or in their own household, we fielded survey instruments to: (i) adolescent girls; (ii) the head of household in which she resides; (iii) her parents if they reside in the same village and are not covered in (ii). 5133 adolescent girls were interviewed, corresponding

\footnotetext{
${ }^{2}$ Such an exercise might have especially high returns in Uganda, a society displaying all of the demographic trends documented above. Indeed, Uganda has amongst the most skewed age distributions of any country. For example, in 2000, 51\% of Uganda's population of 23 million was aged 15 or below. This is even higher than its neighbors - the corresponding figure is $44.9 \%$ in Tanzania and $42.8 \%$ in Kenya, while as a point of comparison, the figure is $21.2 \%$ in the US. Moreover, demographic trends are such that the Ugandan population is expected to become younger overtime. By 2010 it is projected that $66 \%$ of its population will be aged below 15 .

${ }^{3}$ In general, there might also be monetary costs of participation because in principle there is a fixed admission fee of 2000UShs (roughly1.25\$), and a monthly fee of 1000UShs. However, in practice, the majority of girls do not pay the fee. In a small-scale follow-up survey, three quarters of girls were not paying fees.
} 
to around one fifth of all adolescent girls in surveyed villages. Around $10 \%$ of all household heads are surveyed. In the short run, measured a few months after the program's initiation, in treatment villages around 25 girls per village are participating in the ADP. This corresponds to a short run participation rate of $24 \%$, in line with BRAC's ex ante expectation that between 25 and $30 \%$ of eligible adolescent girls would actually participate.

\section{Descriptive Evidence}

\subsection{The Intention to Participate}

We asked adolescent girls about their likelihood to participate in a hypothetical ADP-like programme. We elicited information on both the extensive margin of participation, i.e. whether they intended to participate at all, as well as the intensive margin, i.e. how frequently they expected to participate conditional on attendance. ${ }^{4}$

On the intention to participate, girls were asked to give their likelihood of attendance on a 10-point scale. Adolescent girls are generally optimistic. On average, girls rank the likelihood to be 8.67 out of 10 , although $10 \%$ of respondents provide a ranking of four or below. Given this skewed distribution, we define a respondent to be sure of attending if she responds with 10 the previous question. We then see that around $60 \%$ of girls are certain to participate at least once on the extensive margin. On the frequency of participation, $31.3 \%$ of girls say they will regularly participate, namely, more than three times per week. Hence respondents are more certain to participate per se rather than participate frequently - although $60 \%$ of girls reported to be certain to attend, we note that around two thirds of these girls are unlikely to often attend. We combine responses on the extensive and intensive margins to define an enthusiastic participant as someone reporting they will participate for sure and at least three times per week. On this definition, $21.2 \%$ of girls are enthusiasts, which matches BRAC's ex ante expected participation rate and actual short run participation rates.

\subsection{Perceived Costs and Benefits of Participation}

Table 1 shows girls' main perceived costs and benefits of participation, split between enthusiasts and non-enthusiasts. The most frequently reported cost is that participation would take time from household work. This is significantly higher among enthusiasts. The second most reported cost is that it would take time away from school. This is significantly more likely to be reported as a perceived cost by non-enthusiasts, thus hinting that enthusiasts are less likely to be enrolled in full-time school. ${ }^{5}$ The two most important benefits reported are to learn new skills and make friends. Enthusiasts are significantly more likely to view the main benefit as the acquisition of skills, and significantly less likely to see the formation of friends or to socialize as a major benefit. ${ }^{6}$

\footnotetext{
${ }^{4}$ Enumerators were trained to read a script describing an ADP-like program. On the likelihood of attendance, the question was, "On a scale of $0-10$, where 0 is "I definitely would not join such a club" and 10 is "I definitely would join such a club" how much would you like to join such a club?". On the frequency of attendance, the question was, "If you join, how many times do you think you would go per month?". Possible responses were every day or almost every day; three to five times a week; one or two days a week; two or three days a month; once a month or less; never. The question did not state whether and how much participation would cost. As explained in the main text, in practice many girls do not actually pay to attend the ADC.

${ }^{5}$ Respondents were asked, "what would be the difficulties/costs in joining such a club?". They could list any of the following answers: takes time away from household work (chores), takes time away from my work outside the home, takes time away from my children, takes time away form school, people would disapprove, others (specify).

${ }^{6}$ Respondents were asked, "If you join, what do you think will be the benefits for you?". They could then list as many of the following answers that applied: socialize/make new friends, meet with my current friends, acquire
} 


\subsection{Adolescent Girl and Household Characteristics}

On adolescent girl characteristics, around $70 \%$ are full-time enrolled in school, $8 \%$ have at least one child, and $9 \%$ have a stable partner. Such high levels of school enrolment are fairly consistent with what parents report in the household survey instrument, and from other household surveys from Uganda. Among the non-enrolled, the average years of completed schooling are just over eight so most girls will be literate and numerate. The main activities for the non-enrolled are housework (20\%), looking for labor market work (15\%), and running a small business (9\%).

On characteristics of adolescent girls' households, just over a quarter of households have at least two girls aged between 14 and 20 resident in them, so in the later analysis we check for whether this specific demographic characteristic of households affects the intent to participate. As a measure of household resources we use the log of per capita household expenditures. We use this to shed light on whether adolescent girls from wealthier households have stronger intentions to participate. Finally we note that a quarter of households have some experience with NGOs in general, but not BRAC in particular. We use this to shed light on whether program benefits tend to accrue to those select locations where NGOs already operate.

\section{Empirical Analysis}

\subsection{Correlates of the Intent to Participate}

We estimate the following specification using a linear probability model,

$$
E P_{i h v}=\beta_{i} X_{i v}+\beta_{h} X_{h v}+u_{i h v}
$$

where $E P_{i h v}$ equals one if individual $i$ in household $h$ in village $v$ reports she is enthusiastic, namely she is both certain to attend the club, and to do so at least three times per week, and $X_{i v}$ and $X_{h v}$ are characteristics of individual $i$ and her household respectively. We cluster standard errors at the village level. We later control for village fixed effects. As all right hand side variables are measured before the program is implemented, these cannot be affected by the program itself, nor are these affected by the intention to participate.

Table 2 reports the results. In Column 1 the first set of controls relate to individual $i$ 's demographics that affect the benefits and costs of joining an ADP-like program. We see that girls that are enrolled full-time and those who have a stable partner are $12 \%$ and $7 \%$ less likely respectively, to intend to participate, whereas girls who have children are $9 \%$ more likely to want to participate. Age does not affect the intent to participate, despite the variation in sample girls' ages. To quantify these magnitudes, we note the mean of the dependent variable is .212.

Our survey measures financial and analytic skills using the number of correct answers to everyday financial problems questions and to picture matching questions, respectively. ${ }^{7}$ Financial and analytic skills are both negatively correlated with the intent to participate, but only the effect of analytic skills is precisely estimated. A one standard deviation increase in the analytic skill measure lowers the probability of participation by 3 percentage points - just under $15 \%$ of the sample mean. As quantitative skills are something the ADP aims to improve, on this dimension, the program seems to attract the girls for whom the marginal benefit is higher, assuming there is no skills threshold below which girls would not benefit from participation.

new skills, don't have anything better to do, have fun, it would make my parents happy if I join, it would make my teacher happy if I join, it would make my husband happy if I join, other (specify).

${ }^{7}$ The financial skills score is the sum of correct answers - which could be multiple or open ended - to four finance related questions. The analytical skills score is the sum of correct answers to five questions each asking to select one of six tassels to complete a larger figure. 
The next set of controls analyze the role of the girls' self-reported entrepreneurial skills and gender roles in household income earnings. To measure entrepreneurial skills we asked girls to rank their ability on ten dimensions of business management. ${ }^{8}$ Girls who think they can be successful entrepreneurs are more likely to intend to participate. A one standard deviation increase in the entrepreneurship score raises the probability of participation by $2.2 \%$, that is $10 \%$ of the sample mean. These findings suggest the selection process is quite nuanced: potential participants believe they could be successful entrepreneurs but currently lack the quantitative skills to do so. This is quite different to the nature of self-selection often suggested in microfinance programs, where the most able or entrepreneurial individuals are likely to participate [Banerjee et al 2009].

The next set of controls measures girls' self reported happiness and their satisfaction with family life. In line with the finding that girls who are more confident in their business skills are more attracted by the program, those with a more positive outlook on life are also more likely to want to participate: a one standard deviation in the happiness measure increases the intention to participate by $2.5 \%$. Controlling for overall happiness, a one standard deviation increase in dissatisfaction with their family life increases the intention to participate by $4 \%$. The program might thus attract girls who are less likely to receive livelihood training from their family, or be less satisfied with it, and who are motivated to seek financial independence. Hence accounting for intra-familial relations might be an important part of such programs.

The remaining controls explore the role of household characteristics on the intent to participate. Household size, the years of education of the most educated member, and the presence of other eligible siblings do not affect the intention to participate. On the other hand, the program attracts girls from poorer families: a one standard deviation increase in household per capita expenditures, decreases the intention to participate by $2.6 \%$. This suggests the participation fee is not a binding constraint in practice. Finally, past experience with NGO projects discourages participation. Girls living in households where at least one member has discontinued participation in an NGO project are $7 \%$ less likely to intend to participate.

The result that poorer households are more likely to participate is in line with actual participation decisions in other programs with low take-up rates. For example, Angelucci and Attanasio [2009] find that poorer households are more likely to participate in the Progresa conditional cash transfer program in urban Mexico, a program whose take-up rate is around $50 \%$.

While several individual and household characteristics are significantly correlated with the intention to participate, four stand out as having the strongest impact. The effects of being in school full time and having a child shift the participation probability by half its mean, while having a stable partner, or being in a household with past NGO experience can shift it by one third of its mean. While the first three are key determinants of the cost and benefits of participation, the fact that past NGO experience has such a sizeable impact is certainly surprising and raises the possibility that the success of the program depend on the history of NGO activity in the village.

\subsection{Village Heterogeneity}

Village level factors can also affect girls' intentions to participate. To explore this, Column 2 estimates (1) with village fixed effects. A comparison between Columns 1 and 2 highlight that most individual level determinants are robust to the inclusion of village fixed effects. The two notable exceptions are the effect of having a stable partner - whose coefficient drops by half and

${ }^{8}$ These are: (1) Run your own business; (2) Identify business opportunities to start up new business; (3) Obtain credit to start up new business or expand existing business; (4) Save in order to invest in future business opportunities; (5) Make sure that your employees get the work done properly; (6) Manage financial accounts; (7) Bargain to obtain cheap prices when you are buying anything for business (inputs); (8) Bargain to obtain high prices when you are selling anything for business (outputs); (9) Protect your business assets from harm by others; (10) Collecting the money someone owes you. 
becomes insignificant - and beliefs on gender roles in marriage - whose coefficient doubles and is more precisely estimated. This indicates that marriage norms vary substantially across villages and is consistent with the fact that we have variation in whether villages are located in rural or peri-urban locations, and the predominant religion within the village.

Furthermore, the effect of household wealth and past NGO experience is driven by variation between villages. Hence the program attracts girls from poorer villages, but within village household wealth does not affect the intention to participate. As a corollary, such programs are therefore also unlikely to be captured by wealthy village elites. The fact that the negative impact of previous NGO participation is identified from cross-village variation indicates the effect is not due to idiosyncratic households' responses to NGOs, but rather the effect is common to all village households. This makes the issue of spillovers between NGOs salient, and points to the need for specialized targeting, for instance with dedicated information campaigns, in villages that might have had previous experience with NGOs.

\subsection{Intensive Versus Extensive Margins of Participation}

The remaining Columns focus separately on the intensive and extensive margins of the intent to participate. Columns 3 and 4 reveals that most determinants have the same effect on both margins. In other words, factors that increase the probability of participating per se also increase the intended frequency of participation. However, two exceptions are noteworthy.

First, schooling and age do not affect the probability to participate but girls who are enrolled full-time in school and older girls are less likely to attend frequently. This again suggests the time cost of attendance might be higher for these girls. Second, both the financial skills and the self assessed entrepreneurship score increase the probability of participating but decrease the frequency of participation. This might capture different motives for attending. In particular, girls who are mostly attracted by the financial or business training components of the program might want to attend only on days in which such training takes place. Alternatively it might capture the fact that the most able girls recognize the value of such training opportunities (and so are more likely to attend), but also face the highest opportunity costs of time (and so are likely to attend less often). The final Column shows nearly all of these findings on intentions on the intensive margin go through if we restrict the sample to girls that report the intention to participate for sure.

\section{Discussion}

Our results have implications for the design, management, and evaluation of similar training programs targeted towards adolescent girls in sub-saharan Africa. It is encouraging to see that girls who are likely to have higher returns are more likely to participate, and that girls who are currently in school are less likely to participate. This latter result is reassuring given widespread concerns that the design of these types of program might cause girls to drop out.

On program management, most practitioners are well aware that showing up initially and participating consistently are very different things. Our results show that there can be different characteristics associated with these two decisions, even when just measuring intentions. A somewhat surprising result in terms of program-client interactions is the large negative effect on intentions to participate associated with a prior bad experience with other NGOs. Clearly reputational effects - either of NGOs individually or as a group - are important for future participation. In general, this effect points to the important of assessing prior experience of other organizations in target communities, even if they were not focusing on the same set of interventions.

Finally, the results shed light on the difficulty of evaluating these types of programs with non-experimental methods. As with job training programs generally, selection plays a key role in 
who participates. While our results indicate that some dimensions of skills, ability, and motivation clearly play a role in participation decisions, there are likely to be additional non-measured dimensions at play. Moreover, what we find is that the selection process is quite nuanced: participants want to participate if they lack financial and analytical skills, questions, but also if they have more confidence in their entrepreneurial ability. Hence the direction of bias induced by self-selection is hard to predict. The results in this paper, as well as later work with follow-up surveys will ultimately help us to understand more about the magnitude and direction of the bias.

\section{References}

[1] Angelucci.m and o.Attanasio (2009) "Oportunidades: Program Effects on Consumption, Low Participation, and Methodological Issues", Economic Development and Cultural Change 57: 479-506.

[2] Attanasio.o, A.Kugler, And C.meghir (2008) Training Disadvantaged Youth in Latin America: Evidence from a Randomized Trial, NBER Working Paper 13931.

[3] Banerjee.A, E.Duflo, R.glennerster, And C.kinnan (2009) Preliminary Evidence from the Abdul Jamell Poverty Action Lab Randomized Evaluation of Spandana Microlending, mimeo, MIT.

[4] Bertrand.m, D.Karlan, S.mullainathan, E.Shafir, And J.Zinman (2010) "What's Advertising Content Worth? Evidence from a Consumer Credit Marketing Field Experiment, forthcoming Quarterly Journal of Economics.

[5] Fares.J, J.C.montenegro, And C.orazem (2006) How Are Youth Faring in the Labor Market? Evidence from Around the World, World Bank Policy Research Working Paper 4071.

[6] KATz.E (2008) Programs Promoting Young Women's Employment: What Works, Paper Prepared for the Launch of the Adolescent Girls Initiative, The World Bank.

[7] Madrian.B.C AND D.F.Shea (2001) "The Power of Suggestion: Inertia in 401(K) Participation and Savings Behavior", Quarterly Journal of Economics 116: 1149-87.

[8] moffitt.r (1983) "An Economic Model of Welfare Stigma", American Economic Review 73 : 1023-35.

[9] SAEZ.E (2009) "Details Matter: The Impact of Presentation and Information on the Take-up of Financial Incentives for Retirement Saving", American Economic Journal: Economic Policy 1: 204-28. 


\section{Table 1: Perceived Costs and Benefits of Participation by Enthusiasm}

Means, standard errors in parentheses, p-value on tests of difference in brackets

\section{$\begin{array}{lll}\text { (1) Enthusiast } \quad \text { (2) Non-enthusiast } & \end{array}$}

Test of Equality:

[p-value]

\begin{tabular}{lccc}
\hline Main cost is taking time from household work [yes=1] & .560 & .471 & [.001] \\
Main cost is taking time from school [yes=1] & $.016)$ & $(.009)$ & .430 \\
& .329 & $(.009)$ & {$[.000]$} \\
\hline Main benefit is to acquire new skills [yes=1] & $(.016)$ & .338 & {$[.000]$} \\
Main benefit is to make new friends or socialize [yes=1] & .472 & $(.008)$ & .447 \\
& $(.016)$ & $(.008)$ & {$[.000]$} \\
\hline
\end{tabular}

Notes: An enthusiast is a respondent that reports they would join the club for sure and attend more than 3 times per week. The standard errors on the difference and difference-in-difference are estimated from running the corresponding least squares regression allowing for the errors to be clustered by village. This regression regresses the outcome against a dummy for whether the respondent is an enthusiast. The test of equality $\mathrm{p}$ value relates to the hypothesis that the coefficient on the enthusiast dummy is equal to zero. On the costs of participation, respondents were asked, "what would be the difficulties/costs in joining such a club?". They could then list as many of the following answers that applied - takes time away from household work (chores), takes time away from my work outside the home, takes time away from my children, takes time away form school/school work, people would disapprove, others (specify). On the benefits of participation, respondents were asked, "If you join, what do you think will be the benefits for you?". They could then list as many of the following answers that applied - socialize/make new friends, meet with my 
Table 2: The Intent to Participate

Dependent variable: $=1$ if enthusiast for participation, $=0$ otherwise

Standard errors clustered by village in Columns 1,3 to 5 ; robustly in Column 2

$\begin{array}{llll}\text { (2) Village (3) Will Participate (4) Will Attend (5) Will Attend Regularly } & \end{array}$

\begin{tabular}{|c|c|c|c|c|c|}
\hline & (1) Baseline & Fixed Effects & for Certain & $\begin{array}{l}\text { (4) Regularly } \\
\text { Regla }\end{array}$ & Will Participate for Certain \\
\hline Enrolled full-time in school & $\begin{array}{c}-0.119^{\star * \star} \\
(0.022)\end{array}$ & $\begin{array}{c}-0.141^{\star \star \star} \\
(0.018)\end{array}$ & $\begin{array}{l}0.031 \\
(0.026)\end{array}$ & $\begin{array}{c}-0.166^{* * *} \\
(0.024)\end{array}$ & $\begin{array}{c}-0.215^{\star \star \star} \\
(0.031)\end{array}$ \\
\hline Age (years) & $\begin{array}{l}-0.004 \\
(0.003)\end{array}$ & $\begin{array}{l}-0.006^{* *} \\
(0.003)\end{array}$ & $\begin{array}{r}-0.000 \\
(0.004)\end{array}$ & $\begin{array}{l}-0.008^{* * *} \\
(0.003)\end{array}$ & $\begin{array}{l}-0.008^{* *} \\
(0.004)\end{array}$ \\
\hline Has children [yes=1] & $\begin{array}{c}0.088^{\star * \star} \\
(0.025)\end{array}$ & $\begin{array}{l}0.054^{\star *} \\
(0.026)\end{array}$ & $\begin{array}{l}0.066^{* *} \\
(0.028)\end{array}$ & $\begin{array}{l}0.052^{*} \\
(0.027)\end{array}$ & $\begin{array}{c}0.098^{* * *} \\
(0.035)\end{array}$ \\
\hline Has partner [yes $=1]$ & $\begin{array}{c}-0.065^{\star \star \star} \\
(0.024)\end{array}$ & $\begin{array}{l}-0.030 \\
(0.022)\end{array}$ & $\begin{array}{c}-0.088^{\star \star \star} \\
(0.031)\end{array}$ & $\begin{array}{c}-0.071^{* *} \\
(0.028)\end{array}$ & $\begin{array}{l}-0.071^{*} \\
(0.042)\end{array}$ \\
\hline Financial skills score $[0-4]$ & $\begin{array}{l}-0.011 \\
(0.010)\end{array}$ & $\begin{array}{l}-0.009 \\
(0.007)\end{array}$ & $\begin{array}{l}0.049^{\star \star \star} \\
(0.012)\end{array}$ & $\begin{array}{l}-0.037^{\star \star \star} \\
(0.010)\end{array}$ & $\begin{array}{l}-0.043^{\star \star \star} \\
(0.014)\end{array}$ \\
\hline Analytical Skills [0-5] & $\begin{array}{c}-0.016^{* \star *} \\
(0.006)\end{array}$ & $\begin{array}{l}-0.009^{* *} \\
(0.004)\end{array}$ & $\begin{array}{c}-0.042^{\star \star \star} \\
(0.008)\end{array}$ & $\begin{array}{c}-0.026^{* \star \star} \\
(0.007)\end{array}$ & $\begin{array}{l}-0.005 \\
(0.009)\end{array}$ \\
\hline $\begin{array}{l}\text { Self-assessed entrepreneurship score } \\
{[0-100]}\end{array}$ & $\begin{array}{l}0.001^{*} \\
(0.000)\end{array}$ & $\begin{array}{l}-0.000 \\
(0.000)\end{array}$ & $\begin{array}{l}0.003^{\star \star \star} \\
(0.001)\end{array}$ & $\begin{array}{l}-0.001 \\
(0.000)\end{array}$ & $\begin{array}{l}-0.000 \\
(0.000)\end{array}$ \\
\hline $\begin{array}{l}\text { Who should earn more } \\
\text { [=1 if equal, } 0 \text { if husband] }\end{array}$ & $\begin{array}{l}0.031 \\
(0.019)\end{array}$ & $\begin{array}{l}0.055^{* \star *} \\
(0.013)\end{array}$ & $\begin{array}{l}0.013 \\
(0.026)\end{array}$ & $\begin{array}{l}-0.006 \\
(0.019)\end{array}$ & $\begin{array}{c}0.023 \\
(0.026)\end{array}$ \\
\hline Position on ladder of life [1-10] & $\begin{array}{c}0.014^{\star \star \star} \\
(0.005)\end{array}$ & $\begin{array}{l}0.011^{\star \star \star} \\
(0.004)\end{array}$ & $\begin{array}{c}-0.017^{\star \star} \\
(0.007)\end{array}$ & $\begin{array}{l}0.031^{\star \star \star} \\
(0.005)\end{array}$ & $\begin{array}{l}0.030^{* \star *} \\
(0.007)\end{array}$ \\
\hline Dissatisfaction with family [1-7] & $\begin{array}{l}0.022^{\star \star *} \\
(0.005)\end{array}$ & $\begin{array}{l}0.016^{* \star *} \\
(0.004)\end{array}$ & $\begin{array}{l}0.042^{\star \star *} \\
(0.006)\end{array}$ & $\begin{array}{l}0.014^{* *} \\
(0.006)\end{array}$ & $\begin{array}{l}0.011^{\star} \\
(0.007)\end{array}$ \\
\hline Household size & $\begin{array}{l}-0.003 \\
(0.005)\end{array}$ & $\begin{array}{c}0.002 \\
(0.004)\end{array}$ & $\begin{array}{l}-0.007 \\
(0.006)\end{array}$ & $\begin{array}{l}-0.001 \\
(0.005)\end{array}$ & $\begin{array}{l}-0.002 \\
(0.006)\end{array}$ \\
\hline $\begin{array}{l}\text { Highest years of education of any household } \\
\text { member }\end{array}$ & $\begin{array}{l}0.001 \\
(0.003)\end{array}$ & $\begin{array}{l}0.007^{* \star *} \\
(0.002)\end{array}$ & $\begin{array}{l}-0.004 \\
(0.003)\end{array}$ & $\begin{array}{l}0.004 \\
(0.003)\end{array}$ & $\begin{array}{l}0.005 \\
(0.004)\end{array}$ \\
\hline $\begin{array}{l}\text { Is there another eligible sister in the } \\
\text { household [yes }=1]\end{array}$ & $\begin{array}{c}0.003 \\
(0.015)\end{array}$ & $\begin{array}{l}-0.012 \\
(0.014)\end{array}$ & $\begin{array}{l}0.006 \\
(0.022)\end{array}$ & $\begin{array}{c}0.011 \\
(0.017)\end{array}$ & $\begin{array}{c}0.009 \\
(0.024)\end{array}$ \\
\hline Log per capita household expenditure & $\begin{array}{l}-0.019^{\star \star \star} \\
(0.004)\end{array}$ & $\begin{array}{l}-0.006 \\
(0.004)\end{array}$ & $\begin{array}{l}-0.035^{\star \star \star} \\
(0.008)\end{array}$ & $\begin{array}{l}-0.011^{\star *} \\
(0.005)\end{array}$ & $\begin{array}{l}-0.011^{*} \\
(0.007)\end{array}$ \\
\hline $\begin{array}{l}\text { Number of household members currently } \\
\text { involved with NGO projects }\end{array}$ & $\begin{array}{l}-0.001 \\
(0.015)\end{array}$ & $\begin{array}{l}-0.018 \\
(0.012)\end{array}$ & $\begin{array}{c}0.012 \\
(0.018)\end{array}$ & $\begin{array}{l}0.013 \\
(0.017)\end{array}$ & $\begin{array}{l}-0.007 \\
(0.020)\end{array}$ \\
\hline $\begin{array}{l}\text { Number of household members that have } \\
\text { been involved with NGO projects in the past }\end{array}$ & $\begin{array}{c}-0.069^{\star \star \star} \\
(0.023)\end{array}$ & $\begin{array}{l}-0.021 \\
(0.023)\end{array}$ & $\begin{array}{l}-0.211^{\star \star \star} \\
(0.034)\end{array}$ & $\begin{array}{l}-0.028 \\
(0.029)\end{array}$ & $\begin{array}{c}0.025 \\
(0.047)\end{array}$ \\
\hline Village fixed effects & No & Yes & No & No & No \\
\hline R-squared & 0.056 & 0.157 & 0.117 & 0.048 & 0.061 \\
\hline Number of observations (clusters) & 4825 (149) & $4825(149)$ & 4825 (149) & 4825 (149) & 2942 \\
\hline
\end{tabular}

